\title{
A CONTAÇÃO DE HISTÓRIAS NO INSTAGRAM COMO TECNOLOGIA LEVE EM TEMPOS PESADOS DE PANDEMIA
}

\author{
LA NARRACIÓN DE HISTORIAS EM INSTAGRAM COMO \\ TECNOLOGÍA LIGERA EN TIEMPOS DE PANDEMIA INTENSA
}

\author{
STORTTELLING ON INSTAGRAM AS A LIGHT \\ TECHNOLOGY IN HEAVY PANDEMIC TIMES
}

\author{
Jaileila de Araújo Menezes ${ }^{1}$, Síria Silva Botelho ${ }^{1}$, \\ Roseane Amorim da Silva², Antônio César de Holanda Santos ${ }^{3}$, \\ Daniela Sales de Souza Leão ${ }^{1}$, Victoria Feijó Canales ${ }^{1}$, Helen Leonardo \\ da Silva ${ }^{1}$, Ítala Nathália Ferreira da Silva ${ }^{1}$ e Bruno Vieira dos Santos ${ }^{1}$ \\ ${ }^{1}$ Universidade Federal de Pernambuco, Recife/PE, Brasil \\ ${ }^{\mathbf{2}}$ Universidade Federal Rural de Pernambuco, Serra Talhada/PE, Brasil \\ ${ }^{3}$ Universidade Federal de Alagoas, Palmeira dos Índios/AL, Brasil
}

\begin{abstract}
RESUMO: O artigo objetiva analisar as contribuições da contação de histórias para a saúde mental no contexto da pandemia de Covid-19. Trata-se de uma pesquisa-intervenção que posiciona o recurso das histórias como uma tecnologia leve em saúde, comprometida em reduzir distâncias, criar pontes entre as pessoas através do investimento na produção de vínculos e acolhimento. A contação de histórias articula literatura e psicologia, faz parte da caixa de ferramentas necessárias para a ativação de forças psíquicas expressivas dos afetos no cenário atual. O banco de dados da pesquisa pode ser designado como banco de histórias que passam por um processo de curadoria, sendo essa uma metodologia fundamental para o encadeamento de temas abordados nas histórias e a postagem das mesmas no Instagram do projeto. As histórias videogravadas foram analisadas a partir dos núcleos semânticos contexto-afeto-texto, com destaque para os conteúdos de memória e morte; e práticas de mutualidade em cuidado. A reação dos/as seguidores/as do Instagram expressam mensagens afetuosas aos/as contadores/as.

PALAVRAS-CHAVE: Pandemia; Tecnologia leve em saúde mental; Instagram; Contação de histórias.
\end{abstract}

RESUMEN: El artículo tiene como objetivo analizar las contribuciones de la narración a la salud mental en el contexto de la pandemia Covid-19. Se trata de una investigación-intervención que posiciona el recurso de las historias como una tecnología ligera en salud, comprometida con la reducción de distancias, creando puentes entre las personas a través de la inversión en la producción de vínculos y la acogida. La narración de cuenteros articula la literatura y la psicología, es parte de la caja de herramientas necesarias para la activación de las fuerzas psíquicas expresivas de los afectos en el escenario actual. La base de datos de investigación puede designarse como un banco de historias que se someten a un proceso curatorial, que es una metodología fundamental para vincular los temas tratados en las historias y publicarlos en el Instagram del proyecto. Se analizaron relatos videograbados a partir de los núcleos semánticos contexto-afectotexto; con énfasis en los contenidos de la memoria y la muerte; y prácticas de cuidado mutuo en el cuidado. La reacción de los/las seguidores/as de Instagram expresan mensajes afectuosos a los/las cuenteros/as.

PALABRAS CLAVE: Pandemia; Tecnología ligera en salud mental; Instagram; Cuentacuentos.

ABSTRACT: This article aims to analyze the contributions of the storytelling to mental health in the context of the Covid-19 pandemic. It is an intervention-research that places this story device as light health technology. It is committed to reduce distances, create bridges between people through investment in bonding and welcoming. Storytelling articulates literature and psychology, and is part of the toolbox that is necessary for the activation of expressive psychic forces of affections in the current scenario. The research database can be designated as a bank of stories that undergo a curatorial process, which is a fundamental methodology for linking topics covered in the stories and posting them on the project's Instagram. The videotaped stories were analyzed from mutual-care practices and the context-affection-text semantic nuclei, with emphasis on the contents of memory and death. The reactions of Instagram followers express affectionate messages to the storytellers.

KEYWORDS: Pandemic; Light technology in mental healthcare; Instagram; Storytelling. 


\section{Introdução}

Sonhar e contar mais uma história são algumas das ideias propostas por Ailton Krenak para adiar o fim do mundo (Krenak, 2019). Nesse sentido, a literatura se apresenta como estratégia para preservar e promover espaços-tempos de ruptura com o circuito rotineiro de nossas existências e assim possibilita a abertura de brechas e janelas para problematizarmos o instituído que se manifesta: no ritmo de produtividade, nas diversas paisagens da desigualdade social, principalmente no contexto político-epidemiológico com o qual estamos lidando. O convite para atravessarmos o portal aberto pela linguagem literária pode ter desdobramentos imaginativos de outros mundos possíveis onde desigualdade, egocentrismo, ganância, exploração, individualismo compõem uma língua desconhecida. Contar histórias é um caminho que consideramos potente para metamorfosear relações entre pessoas, entre seres, entre corpo e Terra, na intenção de vivermos de modo responsável com o todo. A reflexão sobre a vida humana na relação com as demais, a noção de coletivo, de dano e vulnerabilidades sem dúvida é um dos legados da pandemia Covid-19.

O reconhecimento de uma pandemia tem gerado alterações significativas na rotina da humanidade: a suspensão do regime presencial de estudos e trabalho, a ruptura do cotidiano marcado pela sociabilidade táctil/presencial e a interrupção do convívio físico com diferentes pessoas da rede de apoio têm motivado um intenso quadro de ansiedade e instabilidade emocional, agravado pela possibilidade de contágio e por um cenário generalizado de incertezas.

Celulares, computadores, redes sociais, aplicativos de reuniões e encontros virtuais mantêm-nos "isolados em conexão". As lives proliferam como um pedido literal de permanência, de vida ou sobrevida diante de medo, incerteza, desamparo social. Em meio ao complexo e intenso mal-estar trazido por um vírus com propriedades orgânicas invisíveis, mas que ganha diariamente dimensões avassaladoras, alimentado pelo clima de instabilidade política e econômica do atual cenário nacional, nossa pesquisa-intervenção em tela busca articular os campos da saúde mental e da literatura, abordando particularmente o recurso da contação de histórias em seus aspectos expressivos e semiótico-elaborativos. A partir daí começamos a pensar sobre como seria contar histórias via Instagram, uma vez que esta prática está enraizada na tradição oral, historicamente situada em contextos narrativos onde as pessoas se dispõem em proximidade física para escutar e ver toda a performance do/a narrador/a. Problematizamos como o contar histórias em tempos de distanciamento físico poderia contribuir para o cuidado em saúde mental, considerando o desafio em bem escolher temas que pudessem expressar as dores e desafios do atual momento.

É importante ressaltarmos que saúde e saúde mental são conceitos complexos e historicamente influenciados por contextos sociopolíticos e pela diversidade de práticas em saúde. No Brasil, o conceito de cuidado em saúde começou a ser entendido de forma mais complexa - considerando os princípios de universalidade, integralidade e equidade - durante a elaboração de uma política de saúde pautada na humanização do serviço. Tais princípios, contudo, coexistem com diferentes abordagens, a exemplo do modelo biomédico. No conceito da Organização Mundial de Saúde (OMS) destaca-se o completo bem-estar físico, mental e social como indicadores de saúde, o que acende muitas críticas dada a impossibilidade de atingi-los totalmente. O termo bem-estar, presente na definição da OMS, é um componente tanto do conceito de saúde, quanto de saúde mental, entendido como um constructo de natureza subjetiva, fortemente influenciado pela cultura. 
A OMS define saúde mental como "um estado de bem-estar no qual um indivíduo percebe suas próprias habilidades, pode lidar com os estresses cotidianos, pode trabalhar produtivamente, e é capaz de contribuir para sua comunidade” (Gaino, Souza, Cirineu, \& Tulimosky, 2018, p. 110).

Entretanto, discutir saúde mental nos tempos atuais significa abordar uma área extensa, abarca mais que pessoas diagnosticadas com transtornos mentais. O termo saúde mental refere-se aos campos do conhecimento, trabalho técnico e políticas públicas de saúde, sendo difícil estabelecer limites para sua definição devido ao seu amplo escopo e por ser baseado em diferentes tipos de conhecimentos como psiquiatria, neurologia, psicologia, filosofia, sociologia e outras (Gaino, Souza, Cirineu, \& Tulimosky, 2018). No presente estudo buscamos contribuir à promoção e prevenção de saúde mental (Rosa \& Miranda, 2017), no sentido de minimizar, através da ferramenta de "Contar Histórias", o sofrimento psíquico advindo dessa nova realidade que estamos enfrentando.

A literatura possibilita que várias reflexões sobre temas sociais sejam abordadas de um modo mais lúdico, poético, mas também questionador das relações sociais. Segundo Antonio Candido (2006), a literatura enquanto arte é social tanto pelo contexto em que é produzida e que se exprime na obra quanto pelo efeito prático que causa naqueles que entram em contato com ela - seja modificando suas visões de mundo ou reforçando o sentimento de certos valores sociais. O compartilhamento de narrativas que abordem os temores intrínsecos à existência e coexistência humanas, bem como histórias sobre a elaboração dos mesmos, pode se mostrar potente para desencadear processos de identificação subjetiva. Estes são fundamentais na construção de resistências ao instituído e permitem vislumbrar outros horizontes semióticos e intervir no círculo de apatia e/ou ansiedade causada em contextos de instabilidade generalizada que desafia nossas crenças de poder sobreviver ao desamparo social.

Em atenção às medidas de cuidado individual e coletivo que nos convocam a permanecer em nossas casas e conservar o distanciamento físico, vislumbramos a contação de histórias para o "bem viver" como um canal que pode contribuir encurtando as distâncias e construindo pontes entre nós. O "Bem Viver" aqui se expressa como Tekó Porã, que em guarani é um conceito filosófico, político e espiritual que se ancora no entendimento da vida como uma teia a conectar todos os seres, tudo o que é vida, a natureza (Takuá, 2018). Optamos por tomar a noção de Bem Viver em uma perspectiva ancestral, considerando suas origens e os sentidos atribuídos por povos originários. As comunidades indígenas do continente latino-americano procuraram construir suas lutas baseando-se em conhecimentos ancestrais, populares e espirituais que sempre estiveram fora do cientificismo próprio da teoria eurocêntrica (Alcântara \& Sampaio, 2017).

O Bem Viver se apresenta como uma oportunidade para construir coletivamente uma nova forma de vida. Não se trata de uma receita expressa em alguns poucos artigos constitucionais e tampouco de um novo regime de desenvolvimento. O Bem Viver é, sobretudo, um processo proveniente da matriz comunitária de povos que vivem em harmonia com a natureza - como os indígenas que

não são pré-modernos, nem atrasados. Seus valores, experiências e práticas sintetizam uma civilização viva, que demonstrou capacidade para enfrentar a modernidade colonial. Com suas propostas, imaginam um futuro distinto que já alimenta os debates globais [...] O Bem Viver - ou melhor, os bons conviveres - é uma 
oportunidade para construir um mundo diferente, que não será alcançado apenas com discursos estridentes, incoerentes com a prática. Outro mundo será possível se for pensado e erguido democraticamente, com os pés fincados nos direitos humanos e nos direitos da natureza. (Acosta, 2015, p. 21)

A literatura nos toca de uma forma própria, convida-nos a um mundo fantasioso onde é possível criar, expressar e elaborar memórias e narrativas. A contação de histórias pode ser utilizada como uma ferramenta de cuidado e promoção do Bem Viver, em sua potência transformadora que media a interiorização e a percepção do mundo em si (Rodrigues, 2020). O contato com uma história é um convite à imaginação e à brincadeira de fazer-se protagonista, (re)contando a sua própria história em cenários imaginativos e encontrar resoluções criativas.

A dimensão de afeto da literatura, sua sensibilidade que transborda em símbolos e figuras de linguagem, faz dela uma pertinente tecnologia no campo da saúde mental. Os saberes em saúde, bem como seus desdobramentos são categorizados por Emerson Elias Merhy (1999) em três modalidades de tecnologias: as tecnologias duras, que envolvem equipamentos, máquinas, saberes materializados; as tecnologias leve-duras, que seriam as normas, os protocolos, o conhecimento clínico e epidemiológico; e as tecnologias leves, que compreendem relações interpessoais, produção de vínculo, acolhimento e que, portanto, prescindem de equipamentos ou protocolos de assistência (Merhy, 1999). Entendemos que a contação de histórias pode compor a caixa de ferramentas das tecnologias leves em saúde.

Lisboa, Santos e Lima (2017) ressaltam que a tecnologia leve é uma ciência subjetiva que produz um compromisso permanente com a tarefa de acolher, responsabilizar, resolver e autonomizar o cuidado. Além disso, quando veiculada e armazenada em redes sociais digitais, ela se caracteriza como um importante recurso de comunicação e de memória coletiva sobre um determinado momento: uma forma de registro do que vivemos, como expressamos e elaboramos estratégias de enfrentamento às adversidades de uma época.

A sinergia entre literatura, histórias para o "bem viver" e saúde mental, anuncia-se no compromisso com as dimensões dialógica, relacional e coletiva que fundamentam as diretrizes de saúde mental neste momento e que inspiram a todas as etapas do nosso projeto intitulado: "A contação de histórias como tecnologia leve no enfrentamento ao sofrimento psíquico da juventude universitária em tempos de pandemia” ${ }^{1}$. No presente texto, objetivamos problematizar uma das dimensões do projeto que é a articulação entre contexto-afeto-texto, abordando um dos temas presentes nas histórias videogravadas e veiculadas no Instagram que é a relação entre morte e memória.

\section{Metodologia}

Para realização do presente estudo nos baseamos na pesquisa-intervenção, modalidade de investigação qualitativa que busca, a partir de situações-problema vivenciadas no contexto pesquisado, oportunizar a análise coletiva de sentidos e práticas produzidos por indivíduos e instituições, visando a transformações macro e micropolíticas (Barros, Paiva, Rodrigues, Silva, \& Leonardo, 2018). A pesquisa e a intervenção são consideradas processos indissociáveis que concomitantemente compreendem e forjam a realidade em 
questão. Consideramos estes dois movimentos como mobilizadores da atividade criadora, em direção à construção de práticas, discursos e ações em diferentes contextos (Cavagnoli \& Maheirie, 2020), os mais desafiadores possíveis como as redes sociais digitais, particularmente o Instagram.

As redes sociais digitais possibilitam conexões entre pessoas e/ou organizações a partir de interesses diversos, como estabelecer e manter relacionamentos de amizade, amorosos, relações de trabalho, compartilhamento de informações e diferentes tipos de conhecimentos. Tais redes têm sido usadas também para realização de protestos políticos, sendo apontadas como nova modalidade de ativismo e militância (Ribeiro \& Moscon, 2018). Quando falamos sobre o Instagram, destacamos seu alcance por ser uma das maiores redes digitais em número de usuárias ${ }^{2}$ na internet; trata-se de um aplicativo baseado em localização móvel que oferece maneiras diferentes de tirar fotos, utilizar ferramentas de edição para transformar a aparência da imagem (filtros), postar vídeos e pequenos textos e compartilhar instantaneamente com as outras usuárias no próprio aplicativo e também em outras redes sociais, como o Facebook e o Twitter (Oliveira, Ribeiro, Morão, \& Machado, 2018).

No Instagram, o perfil da usuária permite a exibição de várias informações pessoais, como o local de trabalho, de estudo e residência, cabendo a ela deixar esses dados expostos ou não. A pesquisa de Ribeiro e Moscon (2018) chama atenção para a exposição em perspectiva positivada, ou seja, predominam postagens/imagens sobre "relacionamento perfeito", conquistas, bens materiais, que são alimentadas por comentários e curtidas elogiosas. Além disso, há a tendência em ocultar informações que são fora dos padrões socialmente valorizados, destacando-se comportamentos conhecidos como politicamente corretos (Ribeiro \& Moscon, 2018).

Observamos que o Instagram tem sido utilizado em diversas iniciativas e projetos de contação de histórias, focados principalmente no público infantil, também mobilizados pelo contexto da pandemia. Muitos desses projetos utilizam o recurso das lives e a maioria é coordenada por mulheres (Avendaño \& Umbelino, 2020; site Lunetas). No entanto, ao não localizarmos estudos publicizados sobre contação de histórias através do Instagram, deparamo-nos com algumas pesquisas que tratam do uso combinado ou não do Facebook, Instagram e YouTube, em diferentes âmbitos sociais e educativos. Os relatos versam sobre (a) os efeitos do uso das mídias sociais digitais por jovens de comunidades periféricas que partilham seus cotidianos, histórias, contexto e práticas de si a partir da construção de um seriado interpretado por elas (Diógenes, 2020); (b) A construção de redes de sociabilidade com foco na autenticidade da imagem e narrativa de si por jovens de escola privada (Ew, Hamann, Gomes, Pizzinato, \& Rocha, 2018); (c) O contexto de formação em saúde como ferramenta de comunicação junto a usuários de comunidades, cujo método inicial de construção da estratégia foi elencar questões sobre como construir o processo, usar a ferramenta para atingir o objetivo e o público almejado (Bernardes, Dias, Pereira, Fernandes, Raimondi, \& Paulino, 2019).

Diante disso, perguntamo-nos: como fazer pesquisa-intervenção usando o Instagram em tempos de pandemia mundial? Como as pessoas participarão do nosso projeto? Como poderíamos interagir com as seguidoras do nosso Instagram? Como contribuir com as reflexões e construções sobre o "Bem Viver" por meio de histórias postadas nessa rede social? Iniciamos o processo de pesquisa-intervenção desafiando-nos a aprender durante o percurso, ou seja, guiando-nos precariamente por mapas, bússolas, GPS, ampulhetas que mais do que indicar o caminho, solicitam-nos que ele seja constantemente produzido. 
Todo o processo de criar a conta do projeto no Instagram (intitulada: Conta.1 história), até a veiculação da história, observação dos comentários e lançamento da janela em Libras fez-nos sistematizar um caminho para a construção de informações da pesquisa, de modo que estabelecemos cinco etapas em nossa rota.

Primeira etapa: divulgação do projeto nas redes sociais. Para isso, utilizamos a rede de contatos do WhatsApp da equipe de pesquisa. A proposta consistiu em convidar estudantes e profissionais de duas instituições públicas de ensino superior de Pernambuco (Universidade Federal de Pernambuco- UFPE; Universidade Federal Rural de Pernambuco - UFRPE/Unidade Acadêmica de Serra Talhada) e uma de Alagoas (Universidade Federal de Alagoas - UFAL/Unidade de Palmeira dos Índios), para que contassem uma história perpassada por uma mensagem sobre o Bem Viver, gravando sua narrativa em vídeo e o encaminhando para o e-mail do projeto. As pessoas interessadas em participar foram orientadas a acessar e preencher um formulário eletrônico que busca coletar informações pertinentes para o projeto - dados gerais, se a pessoa tem ou não conta do Instagram e a validação do pedido de consentimento para a postagem do vídeo e veiculação de sua imagem em demais produtos vinculados ao projeto. A equipe de acolhimento recebe os formulários e fica em contato com as contadoras, ratificando as informações e recolhendo o feedback delas sobre as repercussões da experiência de contar e gravar a história, bem como o acompanhamento dos comentários no Instagram.

No formulário indicamos o modo de gravar o vídeo e também definimos brevemente o princípio do Bem Viver. Esse é um conceito comumente associado à vida saudável e à qualidade de vida, tendo natureza polissêmica, passível de diferentes concepções, como viver melhor, bem-estar e desenvolvimento humano, conforme abordamos na introdução do presente artigo (Alcântara \& Sampaio, 2017). Enquanto equipe estamos empenhadas em defender o sentido ancestral e afro-indígena da concepção de Bem Viver, compondo artesanalmente esse conceito a partir das pistas do indígena e ativista ambiental Ailton Krenak (2019) e das contribuições de Luiz Simas e Luiz Rufino (2019, p. 62) sobre a atitude ecológica: "A presença, o ato, a palavra, a comunicação verbal ou não-verbal são funções de catalisação, imantação e mobilização da vida presente nas mais diversas formas de natureza".

Segunda etapa: os vídeos recebidos pela equipe de acolhimento são enviados para a equipe de curadoria. Buscamos na literatura o que significa o trabalho da curadora e encontramos que a palavra tem origem epistemológica na expressão que vem do latim curator, que significa tutora, aquela que tem uma administração a seu cuidado, sob sua responsabilidade. A curadora de qualquer exposição é sempre a primeira responsável pelas escolhas das obras, da cor das paredes, da iluminação. Potencializando a curadoria em sua dimensão educativa, destaca-se a importância de ações em instituições culturais como museus e centros de artes - nesses, a curadoria educativa tem como objetivo explorar a dimensão artística como veículo de ação cultural (Martins, 2006).

Encontramos também a curadoria digital, termo cujo uso é recente: seu surgimento no Brasil foi em 2004 e veio com a necessidade do monitoramento de novas tecnologias e ferramentas. As profissionais de curadoria digital devem considerar várias políticas e procedimentos na aquisição, gestão e fornecimento de acesso a acervos com materiais digitais (Boeres, 2017). O termo está sendo usado cada vez mais em ações necessárias para manter dados de pesquisa em meio digital e outros materiais ao longo de seus ciclos de vida e do tempo para as gerações atuais e futuras de usuárias (Nunes, Silva, \& Costa, 2020). 
O trabalho de curadoria digital consistiu na sistematização e relação de/entre os dados das histórias, a partir da formulação de uma tabela com cinco entradas, considerando a tríade contexto-afeto-texto e as dimensões macropolíticas, mesopolíticas e micropolíticas de nossa pesquisa-intervenção: (a) título; (b) comentários gerais (temáticas principal e secundárias abordadas na história); (c) relação com as histórias já postadas; (d) indicação de data para postagem a partir do critério de articulação com a história anterior, de forma a manter um encadeamento temático; (e) observações sobre o contex to da contação da história (cenário e performance de quem conta, articulação da história com o momento atual de pandemia e com o cenário mais amplo de instabilidade social, densidade psicológica da história - possíveis forças psíquicas que ela mobiliza).

Todos os vídeos que nos chegam são armazenados no banco de histórias do projeto e as pessoas que enviam são informadas de que eles serão publicados caso atendam ao princípio do Bem Viver e no momento em que a curadoria julgar apropriado, considerando as relações entre contexto (os acontecimentos macro políticos) - afeto (o que a história suscita em termos de forças psíquicas de sofrimento/superação) - texto (elementos presentes na própria narrativa, aspectos dos/as personagens que possibilitem identificações subjetivas estratégicas para o momento e a mensagem da história). O trabalho da curadoria além da catalogação é o encadeamento temático das histórias que serão postadas a cada semana, de modo que seja mantida uma relação entre os temas.

No primeiro ciclo do projeto ${ }^{3}$ recebemos o total de 21 histórias - sendo de 17 narradoras e quatro narradores; nove são estudantes universitárias (dos cursos de Letras, Psicologia, Cinema e Engenharia) e 12 são profissionais (técnicas em educação, docentes e psicólogas). Desse montante, postamos 11 histórias, sendo as demais armazenadas para veiculação no próximo ciclo. Abaixo temos um exemplo do quadro de classificação das histórias já postadas, com as principais temáticas elencadas pela curadoria, o encadeamento das mesmas ao longo das semanas e a provocação/reflexão sugerida a partir de cada narrativa. 
Quadro 1: Histórias postadas no Instagram

\begin{tabular}{|c|c|c|}
\hline $\begin{array}{l}\text { Histórias } \\
\text { postadas }\end{array}$ & Temas suscitados & Provocação sobre as histórias \\
\hline $\begin{array}{l}\text { Carolina e seus } \\
\text { Caracóis }\end{array}$ & $\begin{array}{l}\text { - A literatura como } \\
\text { resistência; } \\
\text { - Os livros como } \\
\text { recursos para lidar } \\
\text { com sofrimentos. }\end{array}$ & $\begin{array}{c}\text { Postagem sobre } \\
\text { Carolina Maria de Jesus. }\end{array}$ \\
\hline As roupas & $\begin{array}{l}\text { - Memória; } \\
\text { - Produzir de } \\
\text { forma coletiva. }\end{array}$ & $\begin{array}{l}\text { Postagem com um convite à reflexão } \\
\text { sobre o que floresce em cada um/a. }\end{array}$ \\
\hline $\begin{array}{l}\text { De quanta terra } \\
\text { precisa o homem? }\end{array}$ & $\begin{array}{l}\text { - Ambição; } \\
\text { - Morte como finitude. }\end{array}$ & $\begin{array}{l}\text { Postagem sobre a função das rou- } \\
\text { pas, as de fora e as de dentro. }\end{array}$ \\
\hline $\begin{array}{l}\text { O dia em que } \\
\text { a morte sambou }\end{array}$ & $\begin{array}{l}\text { - Outra forma de ver a vida; } \\
\text { - A morte não como } \\
\text { finitude. }\end{array}$ & $\begin{array}{l}\text { Postagem sobre Sebastião Salgado } \\
\text { e Chico Buarque, um convite à refle- } \\
\text { xão sobre as desigualdades sociais. }\end{array}$ \\
\hline $\begin{array}{l}\text { O diálogo } \\
\text { entre o capitão } \\
\text { e o marinheiro }\end{array}$ & $\begin{array}{l}\text { - Estratégias para } \\
\text { o cuidado de si e do outro. }\end{array}$ & $\begin{array}{l}\text { Trecho da música do Rappa, para } \\
\text { pensarmos sobre a importância de } \\
\text { nos reinventarmos nessa pandemia. }\end{array}$ \\
\hline $\begin{array}{l}\text { O dilema do } \\
\text { porco-espinho }\end{array}$ & $\begin{array}{c}\text { - Relações humanas; } \\
\text { - Estratégias para } \\
\text { o cuidado de si e do outro. }\end{array}$ & $\begin{array}{c}\text { Trecho de música de Flaíra Ferro, } \\
\text { para refletirmos sobre } \\
\text { a importância da solitude. }\end{array}$ \\
\hline O lixo & - Relações humanas. & $\begin{array}{c}\text { Reflexão sobre aquilo ou aquele/a } \\
\text { que é descartado, excluído na } \\
\text { sociedade. }\end{array}$ \\
\hline $\begin{array}{l}\text { Reflexão sobre } \\
\text { os acontecimentos } \\
\text { da semana }\end{array}$ & $\begin{array}{l}\text { - Luto em relação a Miguel, } \\
\text { e a tantas vítimas de uma } \\
\text { sociedade racista. }\end{array}$ & $\begin{array}{l}\text { Trechos de Cátia de França e de } \\
\text { Jota Mombaça para pensarmos } \\
\text { sobre as vidas que importam. } \\
\text { Vidas negras importam. }\end{array}$ \\
\hline $\begin{array}{l}\text { A Lenda do Sol } \\
\text { e da Lua }\end{array}$ & $\begin{array}{c}\text { - Relação } \\
\text { humano-natureza. }\end{array}$ & $\begin{array}{l}\text { Trecho sobre fala de Ailton } \\
\text { Krenak, e a reflexão ser humano- } \\
\text {-natureza, como um todo. }\end{array}$ \\
\hline Eu te darei o sol & $\begin{array}{c}\text { - Consumismo; } \\
\text { - Relação com a natureza. }\end{array}$ & $\begin{array}{l}\text { Trecho de música de Fagner } \\
\text { e a reflexão sobre a saudade, } \\
\text { o desejo de estar juntos/as. }\end{array}$ \\
\hline Olhos d'água & $\begin{array}{c}\text { - Memória; } \\
\text { - Ancestralidade; } \\
\text { - Desigualdades sociais. }\end{array}$ & $\begin{array}{l}\text { Trecho sobre fala de Conceição } \\
\text { Evaristo, e a importância da } \\
\text { ancestralidade, do reconhecimento } \\
\text { das vidas negras. }\end{array}$ \\
\hline
\end{tabular}


Terceira etapa: os vídeos passam da curadoria para a equipe de edição que faz os ajustes necessários de som, foco de imagem e insere as vinhetas de abertura e fechamento onde constam a logomarca do projeto e informações sobre a história e a contadora.

Quarta etapa: as responsáveis pela arte fazem as postagens dos vídeos e interagem com as pessoas que comentam as histórias. Essa equipe também faz posts semanais sobre a provocação da história publicada. O que estamos chamando de provocação são postagens com informações sobre autoras que tenham relação com as histórias, trechos de músicas, poesias e imagens. Nas provocações, as pessoas são convidadas a comentar como as histórias as tocaram afetivamente, o que se produziu de efeitos a partir do momento em que assistiram aos vídeos. Temos recebido comentários no feed, mas também por direct e algumas pessoas se pronunciaram via WhatsApp, compartilhando suas afetações, memórias e reflexões suscitadas pela narrativa no atual contexto de pandemia. Importante ressaltar a parceria do projeto com o núcleo e acessibilidade e equipe de intérpretes da instituição executora, que têm traduzido os vídeos para a linguagem de Libras, o que demanda também a formulação de uma arte específica.

Quinta etapa: procedemos à análise propriamente dita, uma imersão nas histórias, nos comentários recebidos a partir delas, para conduzir a discussão e reflexão acerca dos possíveis efeitos em quem acessa as narrativas no Instagram e em quem conta as histórias. Vale ressaltar as afetações também na equipe do projeto, que por vezes precisa debater em profundidade sobre as histórias, particularmente as que abordam a opressão em relação à população negra, a articulação humano-natureza, a importância do autocuidado para o cuidado com o outro.

Para o diálogo com esse material estamos nos baseando na análise temática, especificamente na estratégia de codificação tal como proposta por Flick (2009): codificação teórica, codificação temática, análise qualitativa do conteúdo e análise global. Construímos uma codificação reflexiva e fluida do material presente nas postagens, buscando um tratamento interpretativo, criativo e familiarizado sobre os dados, para posterior definição e nomeação dos temas (Souza, 2019). Na operacionalização da análise temática, segundo um processo dinâmico e indutivo de atenção ora concreta em relação à mensagem explícita, ora trazendo as significações não aparentes do contexto (Campos, 2004), os principais temas apreendidos foram: encontro consigo mesmo e com o outro; memória e morte; versatilidade e constância da alma; ambição, ganância e morte; a morte como poética; desenvolvimento de adaptação diante de situações adversas (práticas de autocuidado); a importância e o desafio das relações sociais em situações adversas. Para o presente artigo focaremos na problematização das temáticas sobre memória e morte, considerando o contexto de pandemia.

\section{Resultados e discussão}

\section{Aprendendo a pesquisar no Instagram}

Quando iniciamos o processo de conexão com o mundo online por meio da contação de histórias, não mensuramos quantitativa e qualitativamente a dimensão mesopolítica (condições oferecidas de interação próprias à rede social digital) e micropolítica (sobre as interações em si) que conseguiríamos atingir. Nossa surpresa diante da riqueza de possibilidades discursivas, provocadas pelo ato de contar e compartilhar histórias, deve-se 
ao fato de estarmos imersas em um equipamento de comunicação coletivo e, sobretudo, de relação social, mas agora com objetivo de produzir conhecimento a partir desse campo (Lévy, 1999).

A literatura, nessa perspectiva, contada por diferentes atrizes, articula-se com as percepções das nossas próprias seguidoras afetadas pelo contexto de pandemia. Como equipe, colocamo-nos a refletir sobre "para quem" produzimos os conteúdos, "com o que" e "sobre o que" essas sujeitas estão sendo afetadas.

Identificamos no próprio Instagram uma forma de acessar dados quantitativos que nos ajudassem a responder aos questionamentos acima. Observamos que as dimensões geracionais e de gênero surgem como categorias transversais que permeiam o perfil das nossas seguidoras, além de conseguirmos localizar os territórios em que estão inseridas. É importante pensarmos que a relação entre as territorialidades se conecta com a rede de contatos da equipe de pesquisa e das pessoas que contam as histórias.

Os eixos geográficos que surgiram até então com mais acessos estão localizados nas cidades de Recife e Olinda, no Estado de Pernambuco. Posteriormente, Fortaleza (no Ceará) e João Pessoa (na Paraíba) seguem como a terceira e quarta cidades de maior acesso ao Instagram do projeto. São Paulo (capital) figurou como a quinta e última cidade identificada pela plataforma. Esses dados foram conferidos no dia 19 de junho de 2020, quando houve novas atualizações acerca das informações sobre o nosso perfil nessa rede. Cabe considerar também que, anteriormente, surgiram acessos nas cidades de Arapiraca (em Alagoas) e Serra Talhada (em Pernambuco), colocando o nosso eixo territorial conectivo centrado na região nordeste.

A plataforma também permite acessar o perfil em termos de idade e gênero, com a ressalva sobre a categorização binária (homem/mulher) quanto a este marcador social, não sendo possível situarmos outras experiências de corpo (Butler, 2003). Sobre a faixa etária, registramos uma maior concentração de seguidoras e de pessoas que interagem com os conteúdos entre 25 e 34 anos, tendo maior participação de mulheres. A segunda faixa etária mais presente está entre os 18 e os 24 anos com o recorte de gênero masculino. Considere-se, ainda, que no total de interações a maior porcentagem está entre as mulheres: $78 \%$ de seguidoras e comentadoras ${ }^{4}$. Os dados apresentam a participação em peso de jovens, pessoas mais afeitas à interação nas tecnologias de informação e comunicação como o Instagram. A Política Nacional de Juventude (PNJ) divide esse recorte geracional em jovens-jovens (de 18 a 24 anos) e em jovens-adultos (de 25 a 29 anos). Tais informações nos permitem dizer que nosso perfil tem sido acessado, majoritariamente, por mulheres jovens-adultas (25 a 29 anos) e adultas (30 a 34). Consideramos esse dado significativo para aprofundamento em artigos futuros, onde possamos relacionar melhor o número de mulheres que até então contaram histórias em comparação com o número de homens e as reações e comentários quanto ao gênero. Para o momento refletimos que a contação de histórias em uma perspectiva de tecnologia leve em saúde mental ganha fortes contornos de acolhimento e de produção de vinculação afetiva, comprometida com o cuidado de si e do outro - todos esses signos estão associados a performances de feminilidade no contexto de sociedades capitalistas e heteropatriarcais como a que vivemos.

No total registramos 528 pessoas seguindo a página do projeto no Instagram, sendo que o número de acessos tem variado durante as semanas e de acordo com as histórias postas, como no caso da narrativa "A lenda do sol e da lua", ocasião em que acompanhamos 
761 visualizações. Não temos como certificar todas as variáveis que fazem uma história ter mais acessos do que outras, mas inferimos que uma delas se refere à rede de contatos das próprias contadoras que, quanto maior, mais acessos garante.

As novas estratégias possibilitadas pelo espaço virtual surgem como um meio de aproximação entre as pessoas e as diversas culturas que se apropriam da oralidade, um modo de ver e entender o mundo sem abrir mão da tão fecunda e antiga forma de contar histórias. Santos e Gerlin (2018) realizaram uma pesquisa sobre contação de histórias no Youtube e obtiveram como resultado o destaque da rápida repercussão proporcionada pelo ambiente virtual, sendo essa uma boa alternativa para a divulgação da arte e do trabalho de Narrar Histórias. Em uma pesquisa realizada por Porto (2018) observou-se que o Instagram contribui com a produção de conteúdo pedagógico, de informação, leitura e promove comunidades de aprendizagem, compartilhamentos e acolhimentos por meio da interação entre as participantes. Consideramos a positividade desses aspectos sobretudo nesse período de pandemia e distanciamento físico entre pessoas.

\section{Histórias na pandemia, ou o que aFEta a nós!}

Passamos agora a refletir "com o que" e "sobre o que" nossas seguidoras são afetadas em tempos de pandemia. Considerando os pressupostos da análise temática, destacamos elementos das postagens a respeito de memória e morte, buscando contar uma história sobre esses dados (Souza, 2019). A partir dos diversos comentários presentes nas postagens, optamos por algumas que, de alguma forma, exprimem os efeitos das narrativas contadas e ouvidas sobre as comentadoras e contadoras.

Ao atuarmos em um contex to de pandemia de Covid-19, diversas questões sobre memória e morte têm sido mobilizadas em todas nós. Há o entendimento, segundo Márcia D’Aléssio (1993) com base em Jean Duvignaud e Maurice Halbwachs, de que nos momentos históricos de ruptura do ritmo costumeiro de nossas existências os temas da memória e durabilidade ganham relevo. A terminalidade da vida, a morte e o luto, experiências tão intensas da sociabilidade humana, têm sido guiadas por protocolos sanitários que impõem a urgência da despedida, o que faz com que essa mesma fique em suspensão simbólica. Falecer em tempos de Covid-19 tem exigido da Psicologia novos procedimentos para a condução do luto (Crepaldi, Schmidt, Noal, Bolze, \& Gabarra, 2020).

No que toca especificamente à morte, destacamos dos dados da pesquisa duas postagens. Na quinta semana do projeto veiculamos a história "O dia em que a morte sambou", escrita por Habib Zahra e ilustrada por Valeria Rey Soto (Zahra \& Soto, 2016), com narrativa feita por uma professora universitária. O personagem principal, Seu Biu, é um senhor já com "idade avançada” que vive dançando em seu território, encantando e levantando questões por onde passa, até que o encontro com a morte acontece, mas marcado por prazer e alegria ao invés da repulsa - costumeira em nossa cultura. Nas postagens percebemos que os comentários remetiam a memórias da infância vivenciada em lugares interioranos, onde a velhice tem mais graça e formosura do que na cidade grande. A forma festiva de lidar com a morte, mais como celebração da vida e com menos fatalismo parece ter relação com uma vida bem vida, tanto em tempo - dada a idade avançada que o personagem atinge quanto em qualidade, bom humor e leveza de um espírito vigoroso e em relação plena com seu território existencial. 
Uma história contagiante: nos revela que para estar diante dos curtos momentos de felicidade/alegria não importa idade, muito menos entidade 승. Seu Biu quebra todos os paradigmas de expectativas estereotipados ao grupo idoso. (Comentador da postagem).

Viajei até minha infância no interior e lembrei de um senhor cego (não recordo seu nome) q estava sempre com um pandeiro, cantando suas emboladas e que passava todos os dias na minha rua. A gente (as crianças) ficávamos encantadas, tentando entender como um cego tocava pandeiro, sabia o caminho de casa e ainda nos reconhecia! Sempre cantava "bulindo" com a gente. Vou procurar saber dele. Infância querida. Parabéns e obrigada Contadora. Tou adorando o projeto. $\odot \diamond$ (Comentadora da postagem, grifo nosso).

Em pesquisa sobre os efeitos da contação de histórias, Oliveira e Rocha (2016, p. 97) nos dizem que "as histórias produzem transformações na medida em que estimulam a pensar em sentidos inéditos para a experiência passada, a partir do ponto de vista presente”. Os comentários acima nos revelam que, ao ativar memórias, é possível também acionar processos imaginativos, ressignificações e novas possibilidades de viver inspiradas por atitudes promotoras de saúde mental.

Outra postagem sobre morte ocorreu na semana em que o menino Miguel Otávio Santana da Silva faleceu após cair do nono andar de um prédio de luxo na cidade do Recife, local em que sua mãe trabalhava como empregada doméstica - mesmo em período de pandemia. O fato teve ampla repercussão nacional e internacional, e aconteceu na semana de grande mobilização e protestos antirracistas devido ao assassinato de George Floyd (homem afroamericano que foi asfixiado durante abordagem truculenta policial em Minneapolis, EUA). A morte de Miguel, resultado da irresponsabilidade e negligência da patroa de sua mãe (primeira-dama de Tamandaré, município localizado no litoral sul de Pernambuco), escancarou uma de nossas feridas coloniais. O racismo estrutural no Brasil tem assassinado cada dia mais e se agravou com o genocídio da população negra durante a pandemia de Covid-19. Visceralmente afetada por estes ocorridos, a equipe de pesquisa trocou várias mensagens pelo grupo do WhatsApp e tomou a decisão de não veicular nenhuma das histórias do acervo. A equipe de arte reuniu nossas narrativas de dor e encadeou cada frase que registramos de luto empático (Crepaldi et al., 2020) e compromisso com a luta antirracista. Entendemos que foi (e que ainda está sendo durante esta escrita) um luto que se tornou também uma memória vivida e coletiva (D’Aléssio, 1993).

Durante todo o projeto essa foi uma das postagens que teve menos curtidas e apenas um breve comentário público - "eu tenho pressa e nós vamos cobrar" -, na verdade a replicação de um trecho da nossa história veiculada. Consideramos que esse comentário reverberou a alternativa que elaboramos para nos posicionarmos diante daquele roubo da vida. Os silêncios e as poucas curtidas podem também representar o incômodo gerado pela situação de violência, de racismo e da própria morte. Para nós foi fundamental não fugir à realidade do óbito por entendermos que "a morte é uma ponte para a vida" (Arantes, 2016, p. 12), ou seja, vivenciar esse luto e constituir uma memória sobre o ocorrido possibilita a afirmação de compromisso com as vidas negras que para nós importam!

Ainda no que toca à memória, outros elementos nos chamaram atenção nas postagens, por fazerem referência a elementos de afirmação da vida e de reflexividade. Um dos exemplos é o vídeo em que o narrador declama o poema "As roupas", de Luiz Guilherme Paiva (2011), 
extraído da obra Poemas para vestir. Os comentários sobre sua contação remeteram a diversas lembranças despertadas nas pessoas sobre situações cotidianas interrompidas por conta da pandemia, memórias da produção de roupas junto a familiares, o que instaurou uma atmosfera nostálgica na tela.

Que lindo! Lembrei da minha avó que era costureira. Que boa lembrança dos fuxicos que fazíamos juntas. (Comentadora da postagem).

Que lindo! Que contação "suave”, num poema tão cheio de memórias... Curti demais a sua interpretação ....! (Comentadora da postagem).

Domingo estive bem nostálgica. Ao passar os dedos por entre as "roupas de sair" encontrei minha alma alegre, fagueira e dançante colada no meu vestido estampado... quando tudo isso passar com certeza o vestirei para bailarmos pelas ruas do Recife. bjs Contador. (Comentadora da postagem).

Durante muito tempo a memória era o único recurso de armazenamento e transmissão de conhecimento. Era através das narrativas orais que as pessoas se apoderavam de informações diversas. Eram os narradores os responsáveis por discutir fatos, encadear acontecimentos, perpetuar crenças e manter as tradições. Narrar em espaço virtual produz significativas mudanças no processo de "contação", mas pensamos que algo muito valioso se mantém e nos conecta em vários níveis, produzindo a disposição para a escuta de valores, ideias, conceitos, tradições e por que não dizer de afetividades (Baptista, 2017).

Uma postagem que também ativou elementos de memória foi a provocação inspirada em Lia de Itamaracá ${ }^{5}$, na qual destacamos comentários sobre lembranças do prazer de dançar ciranda.

A ciranda me acompanha desde criança, se fez viva na escola e ainda durante toda a minha graduação me reinventei tantas vezes nesse meio tempo... é possível até ouvir a voz de Lia, seria essa a música a animar o corpo de Seu Biu? não duvido... (Comentadora da postagem).

O dançar nos aproxima da sublimação, e quando dançado em grupo ou em dupla tornamo-nos um só: assim nos deixa nostálgicos, neste momento de coronavírus, pela impossibilidade desse ato único. E também nos mostra quanto valor tem o valor da preservação. (Comentador da postagem).

Como diz Márcia D’Aléssio (1993), essas postagens representam elementos da coletividade que são os fundamentos da sustentação da memória, pois mesmo tendo seguidoras e comentadoras diversas em nosso perfil do Instagram, e considerando a situação de isolamento social provocado pela pandemia, o desejo de estar junto e em celebração pode ganhar alguma densidade e expressão. Afirmação de potência de vida, instituição imaginária do tempo de festividade em forma de dança que coletiviza expectativas de um mundo melhor, capaz de afirmar o Bem Viver para populações historicamente subalternizadas. Destacamos as possíveis e múltiplas articulações entre Psicologia e Literatura enquanto áreas que colocam em disposição ferramentas para nos auxiliar na expressão e elaboração de nossos afetos (Oliveira, 2014). 
Em outro estudo, Nascimento e Oliveira (2016) afirmam que narrativas construídas a partir de objetos que ativam memórias de afeto produziram benefícios em usuários de serviço de saúde da atenção básica. Nesse contexto, a contação de histórias compôs uma das práticas integrativas e complementares promotoras de saúde. Essa compreensão leva-nos a inferir que diversas manifestações afetivas das seguidoras têm significado, em alguma medida, a produção de benefícios para saúde mental delas, e também para quem conta as histórias.

\section{Considerações finais}

Em meio aos impostos desafios, incertezas e dores, nossa pesquisa-intervenção buscou contribuir com a problematização das tecnologias leves em saúde mental, através da contação de histórias, ocupando ciberespaços e uma cibercultura para nos mantermos “isolados em conexão”. A tecnologia digital, nessa direção, propiciou a articulação ética-política-estética entre a arte literária e a psicologia. Assim, a literatura, na condição de agregar ideias e a produção cultural de grupos sociais específicos foi vinculada ao método “curadoria em psicologia”, que envolve o compromisso não só com o conteúdo das histórias, mas também com as pessoas que as recepcionam, elegendo materiais que zelam pela integridade psicológica (Mendonça, Menon, Oliveira \& Catelão, 2017) e que contenham aspectos animadores das forças psicopolíticas de resistência.

Nesse sentido, ocupar o Instagram em tempos de pandemia, uma das maiores redes sociais em número de usuárias na internet, resultou nas indagações que permearam este texto e nossa prática de produção de conhecimento na academia. Configurou também um desafio à reinvenção do fazer pesquisa-intervenção no campo da saúde mental frente às limitações e possibilidades da própria plataforma e das interações "entre telas" do contexto virtual. Além disso, oportunizou utilizar esta rede social como instrumento de encontro, comunicação e memória coletiva inserida e dialogada com a conjuntura social no cotidiano das pessoas.

Interessante observar os dados coletados na plataforma que indicam a predominância de pessoas conectadas ao perfil do Instagram serem de jovens seguidoras mulheres (dentro da perspectiva binária de gênero - homem e mulher) concentradas na região nordeste do país. Este maior alcance do gênero feminino na produção e consumo literário, embora implique contraposição ao "cistema" hetero-capitalista-patriarcal, sinaliza também uma prática marcada pela expressão afetiva, condição associada a performances de feminilidade, justificando parte direta e/ou indiretamente a menor conexão de usuários identificados como homens.

Sugerimos, a partir da análise temática, que os aspectos das afetações provocadas e sentidas mobilizaram recorrentemente aos temas de memória, morte e saudade. Esses nichos temáticos aparecem em rupturas da dita normalidade dos processos (Duvignaud \& Halbwachs, citados por D’Aléssio, 1993), característica do momento pandêmico atual de instabilidade e desamparo social. Ainda assim, a literatura no formato das publicações na página - que compreende as contações em língua portuguesa (1), as narrativas correspondentes em Libras (2) e as publicações de provocações referentes às histórias (3) - possibilitou abordagens poéticas, criativas e estratégicas como protocolos assistenciais interventivos.

Julgamos que este trabalho se inscreve na possibilidade histórica de significar quais lutas são possíveis conforme as restrições em tempos de pandemia. Nosso grupo se soma a outros coletivos interessados em fazer valer o momento vivido por quem permanece em 
vida e por todas as pessoas que se fazem presentes em nossas memórias, a retroalimentar resistências e construções históricas promissoras como outras possibilidades estéticas de fortalecimento da luta contra projetos genocidas e necropolíticos.

Sob essa perspectiva, evitamos cair na armadilha de situar a localização do sofrimento apenas nas pessoas e em suas características individuais, abandonando-as à sua própria sorte, e somos instigadas a considerar que as dores do momento atual estão mediadas pela injustiça social, expressas na falta de reconhecimento, exclusão, não atendimento de necessidades e direitos básicos e na desvalorização de certas vidas. Compreendemos que perpetuar narrativas sobre o Bem Viver (e mesmo as que o problematizam) elaboradas com base na afetação e tecidas como instrumentos de cuidado pode possibilitar atenção à saúde mental e afirmações das (r)existências.

O conceito do Bem Viver, basilar à construção e desenvolvimento deste projeto, provocou também o questionamento das diversas interações e afetações dos vínculos entre nós, equipe técnica, contadoras e seguidoras. A teia de relações desses grupos e os seus modos de sentir, comunicar, relacionar e integrar corpo-Terra, na intenção de viver em coletividade e de forma mais justa fazem parte do compromisso ético-estético-político de nossa pesquisa-intervenção. Sentimo-nos implicadas com a mudança social, com a possibilidade de contar mais uma história que possa servir como vacina capaz de produzir os anticorpos necessários para fazer valer a vida nessa Terra.

\section{Notas}

1 A contação de histórias como tecnologia leve no enfrentamento ao sofrimento psíquico da juventude universitária em tempos de pandemia - projeto de pesquisa cadastrado no CAAE: 35080620.3.0000.5208, com financiamento próprio da equipe de pesquisa.

2 O sujeito de linguagem predominante no texto será o gênero feminino, quando não utilizaremos as duas designações o/a em coerência à escrita de inspiração feminista que orienta esse texto.

3 O projeto acontece em dois ciclos, tendo o primeiro já se encerrado no que tange ao recebimento de histórias. O segundo ciclo será iniciado no mês de agosto do presente ano. Vale informar que as histórias são veiculadas nas sextas-feiras, desde o dia 10 de abril.

4. O perfil do nosso Instagram é público e, por isso, permite a qualquer pessoa cadastrada na plataforma que comente e curta as postagens. Por isso fizemos essa pequena diferenciação entre seguidoras e comentaristas.

5 Lia de Itamaracá é cirandeira, cantora, dançarina, atriz e ex-merendeira, mulher negra nascida em 12 de janeiro de 1944, na Ilha de Itamaracá-PE. Tem diversos discos lançados cantando cirandas compostas por ela e por outras cirandeiras. Em 2005 foi reconhecida como Patrimônio Vivo de Pernambuco. Para mais informações, ver seu perfil no Instagram (@liadeitamaracaoficial)e em seu site: http://liadeitamaraca.com.br/. 


\section{Referências}

Acosta, Alberto. (2015). O Bem Viver: Uma oportunidade para imaginar outros mundos. Teresina: Elefante.

Alcântara, L. C. \& Sampaio, C. A. C. (2017). Bem Viver: uma perspectiva (des) colonial das comunidades indígenas. Rev. Rupturas, 7(2), 1-31. http://dx.doi.org/10.22458/rr.v7i2.1831.

Arantes, A. C. Q. (2016). A morte é um dia que vale a pena viver (1a ed.). Rio de Janeiro: Casa da Palavra.

Avendaño, A. C. \& Umbelino, T. (2020, 27 de abril). Contadores de histórias de Brasília promovem lives literárias na internet Durante a pandemia, contadores de histórias... Correio Braziliense, Brasília, DF. Recuperado de https://www.correiobraziliense.com.br/app/noticia/cidades/2020/04/27/interna cidadesdf,848594/

Barros, J. P. P., Paiva, L. F., Rodrigues, J. S., Silva, D. Barbosa, \& Leonardo, C. S. (2018). Pacificação nas periferias: discursos sobre as violências e o cotidiano de juventudes em Fortaleza. Revista de Psicologia, 9(1), 117-128. Recuperado de http://www.periodicos.ufc.br/psicologiaufc/article/view/30781.

Baptista, E. S. (2017). Uso da contação de histórias no atendimento psicopedagógico. Diálogos Interdisciplinares, 6(2), 1-12. https://revistas.brazcubas.br/index.php/dialogos/article/view/308.

Bernardes, V. P., Dias, L. F., Pereira, M. A., Fernandes, M. E., Raimondi, G. A., \& Paulino, D. B. (2019). Facebook® como ferramenta pedagógica em saúde coletiva: Integrando Formação Médica e Educação em Saúde. Revista Brasileira de Educação Médica, 43(1, Supl. 1), 652-661. Epub January 13, 2020. https://doi.org/10.1590/1981-5271v43suplemento 1-20190192

Boeres, S. A. A. (2017). Competências para equipes de profissionais no contexto da preservação digital. Tese de Doutorado, Programa de Pós-graduação em Ciência da Informação, Universidade de Brasília, Brasília, DF.

Butler, J. (2003). Problemas de gênero: feminismo e subversão da identidade. Rio de Janeiro: Editora Record.

Candido, A. (2006). Literatura e sociedade. Rio de Janeiro: Ouro sobre Azul.

Campos, C. J. G. (2004). Método de análise de conteúdo: ferramenta para a análise de dados qualitativos no campo da saúde. Rev. Bras. Enferm., 57(5), 61 1-614. https://www.scielo.br/pdf/ reben/v57n5/a19v57n5.pdf.

Cavagnoli, M. \& Maheirie, K. (2020). A cartografia como estratégia metodológica à produção de dispositivos de intervenção na Psicologia Social. Fractal: Revista de Psicologia, 32(1), 64-71. https://doi.org/10.22409/1984-0292/v32i1/5680.

Crepaldi, M. A., Schmidt, B., Noal, D. S., Bolze, S. D., \& Gabarra, L. M. (2020). Terminalidade, morte e luto na pandemia de Covid-19: demandas psicológicas emergentes e implicações práticas. Estudos de Psicologia (Campinas), 37, e200090. Epub June 01, 2020. https://dx.doi. org/10.1590/1982-0275202037e200090

D’Aléssio, M. M. (1993). Memórias: leituras de M. Halbwachs e P. Nora. Revista Brasileira de História,13(25/26), 97-103. 
Diógenes, G. (2020). Cidade, arte e criação social: novos diagramas de culturas juvenis da periferia. Estudos Avançados, 34(99), 373-390. Epub July 10, 2020. https://doi.org/10.1590/s0103$\underline{4014.2020 .3499 .022}$

Ew, R. A. S., Hamann, C., Gomes, G. A., Pizzinato, A., \& Rocha, K. B. (2018). Mídias sociais: construção de narrativas de si de adolescentes. Psicologia Eீ Sociedade, 30, e169654. Epub June 07, 2018. https://doi.org/10.1590/1807-0310/2018v30169654

Flick, U. (2009). Introdução à Pesquisa Qualitativa (3a ed.). Porto Alegre: Artmed.

Gaino, L. V., Souza, J., Cirineu, C. T., \& Tulimosky, T. D. (2018). O conceito de saúde mental para profissionais de saúde: um estudo transversal e qualitativo. SMAD. Revista eletrônica saúde mental álcool e drogas, 14(2), 108-1 16. https://dx.doi.org/10.11606/issn.1806-6976.smad.2018.149449.

Krenak, A. (2019). Ideias para adiar o fim do mundo. São Paulo: Companhia das Letras.

Lévy, P. (1999). Cibercultura. São Paulo: Editora 34.

Lisboa, N. A., Santos, S. F., \& Lima, E. I. (2017). A importância das tecnologias leves no processo de cuidar na atenção primária em saúde. Textura, 10(19), 164-171. https://textura.emnuvens. com.br/textura/article/view/53.

Martins, M. C. (2006). Curadoria educativa: inventando conversas. Reflexão e Ação, 14(1), 9-27.

Merhy, E. E. (1999). O ato de governar as tensões constitutivas do agir em saúde como desafio permanente de algumas estratégias gerenciais. Ciência Ẽ Saúde Coletiva, 4(2), 305-314. https://dx.doi.org/10.1590/S1413-81231999000200006.

Mendonça, G. P., Menon, M. C., Oliveira, M. M., \& Catelão, E. M. (2017). A curadoria da literatura na educação básica: aproximações entre os booktubers e docentes. Texto Digital (Florianópolis), 1(1), 201-221.

Nascimento, M. V. N. \& Oliveira, I. F. (2016). As práticas integrativas e complementares grupais e sua inserção nos serviços de saúde da atenção básica. Estudos de Psicologia (Natal), 21(3), 272-28 1. https://doi.org/10.5935/1678-4669.20160026

Nunes, M. F., Silva, A. C. P., \& Costa, L. F. (2020). Memória e curadoria digital de museu e patrimônio: Avaliação de usabilidade $360^{\circ}$. Revista de Ciências e Tecnologias de Informação e Comunicação, 1(41), 191-215. https://doi.org/10.21747/16463153/41a101.

Oliveira, É. C. S. (2014). Contando estórias e inventando metodologias para discutir a violência contra as mulheres. Revista Estudos Feministas, 22(1), 195-214. https://doi.org/10.1590/S0104-026X2014000100011.

Oliveira, É. C. S. \& Rocha, K. A. (2016). Sobre cafundós, confins, fronteiras: contações de histórias sobre diversidade sexual. Psicologia E Sociedade, 28(1), 94-104. https://doi.org/10.1590/1807$\underline{-03102015 \mathrm{v} 28 \mathrm{n} 1 \mathrm{p} 094}$

Oliveira, V. A., Ribeiro, A. L., Morão, L. B., \& Machado, A. A. (2018). A utilização do Instagram por atletas olímpicos brasileiros: perfil traçado por uma análise de imagens. Revista Interamericana de Comunicação Midiática, 17(33), 194-211. https://doi.org/10.5902/2175497723213.

Paiva, L. G. (201 1). Poemas para Vestir. São Paulo: Estação das Letras e Cores.

Porto, B. R. C. (2018). Uso do Instagram na produção de conteúdos pedagógicos, informação e leitura. Trabalho de Conclusão de Curso (Especialização em Linguagens e Educação), Universidade Federal de Santa Catarina, Florianópolis, SC. https://repositorio.ufsc.br/handle/123456789/201075 
Ribeiro, M. P. \& Moscon, Daniela. (2018). Reflexões sobre o uso do Instagram na contemporaneidade. Revista Unifacs, 17(1), 35-56. http://www.revistas.unifacs.br/index.php/sepa.

Rodrigues, L. O. (2020). Prefácio. In J. Menezes, E. Rosa, Silva, \& K. Barbosa (Orgs.), TramAções Feministas: diversidade na literatura para crianças e jovens (pp. 8-11). Recife: Editora UFPE.

Rosa, Á. L. \& Miranda, A. V. S. (2017). O yoga como prática integrativa na promoção de saúde mental: uma ferramenta ética para o cuidado de si. Rizoma, 1(2), 178-190. http://periodicos. estacio.br/index.php/rizoma/article/view/3180/alvaro.

Santos, E. M. \& Gerlin, M. N. M. (2018). Trocas de experiências no campo da contação de histórias: colaboração e oralidade no ambiente digital do Youtube. In M. N. M. Gerlin (Org.), Competência em informação e narrativa numa sociedade conectada por redes (pp. 133-158). Brasília, DF: Faculdade de Ciência da Informação, Universidade de Brasília. http://repositorio.unb.br/ handle/10482/32742.

Souza, L. K. (2019). Pesquisa com análise qualitativa de dados: conhecendo a Análise Temática. Arquivos Brasileiros de Psicologia, 7 1(2), 51-67. Recuperado de http:// pepsic.bvsalud.org/scielo. php? script $=$ sci arttext\&pid=S1809-52672019000200005\&lng=pt\&tlng=pt.

Simas, L. A. \& Rufino, L. (2019). Flecha no tempo. Rio de Janeiro: Mórula Editorial.

Takuá, C. (2018). Teko Porã, o sistema milenar educativo de equilíbrio. Rebento, 9, 5-8.

Zahra, H. \& Soto, V. R. (2016). O dia em que a morte sambou. São Paulo. Riccardo Zahra.

\section{JAILEILA ARAÚJO MENEZES \\ https://orcid.org/0000-0003-3322-3764}

Professora Associada da Universidade Federal de Pernambuco, Doutora em Psicologia pela Universidade Federal do Rio de Janeiro. Endereço: Avenida da Arquitetura, s/n | Cidade Universitária | Recife-PE | CEP 50740-550. E-mail: jaileila.araujo@gmail.com

\section{SÍRIA SILVA BOTELHO \\ https://orcid.org/0000-0002-1486-4710}

Psicóloga na Universidade Federal de Pernambuco, vinculada à Pró-Reitoria para Assuntos Estudantis. Mestre em Psicologia Social pela Universidade Federal de Pernambuco.

E-mail: siriadomundo@yahoo.com.br

\section{ROSEANE AMORIM DA SILVA}

https://orcid.org/0000-0002-1454-0417

Professora Adjunta da Universidade Federal Rural de Pernambuco-UFRPE/ Unidade Acadêmica de Serra Talhada - UAST e Doutora em Psicologia pela Universidade Federal de Pernambuco.

Email: roseaneamorims@gmail.com 


\section{ANTÔNIO CESAR DE HOLANDA SANTOS}

https://orcid.org/0000-0002-9516-7035

Professor Adjunto do Curso de Psicologia da UFAL - Campus Arapiraca, na Unidade Educacional de Palmeira dos Índios. Doutor em Psicologia pela Universidade Federal de Pernambuco.

E-mail: cesarholanda@gmail.com

\section{DANIELA SALES DE SOUZA LEÃO}

https://orcid.org/0000-0002-1525-0702

Doutoranda em Psicologia pela Universidade Federal de Pernambuco e mestre em Antropologia pela mesma instituição.

Email: danielasalespsi@gmail.com

\section{VICTORIA FEIJÓ CANALES}

https://orcid.org/0000-0001-8602-9506

Mestranda em Psicologia pela Universidade Federal de Pernambuco (UFPE). Bacharel em Psicologia pela mesma instituição.

E-mail: v.feijo.canales@gmail.com

\section{ÍTALA NATHÁLIA FERREIRA DA SILVA \\ https://orcid.org/0000-0002-2545-3343}

Graduanda em Psicologia pela Universidade Federal de Pernambuco.

E-mail: italanathaliafs@gmail.com

\section{HELEN LEONARDO DA SILVA}

https://orcid.org/0000-0002-3346-6822

Graduanda em Psicologia pela Universidade Federal de Pernambuco

E-mail: helenlisva@gmail.com

\section{BRUNO VIEIRA DOS SANTOS \\ https://orcid.org/0000-0003-1572-1938}

Doutorando em Psicologia pela Universidade Federal de Pernambuco (UFPE). Mestre em Psicologia pela Universidade Federal de Minas Gerais (UFMG). Bacharel em Comunicação Social / Jornalismo pela UFMG.

E-mail: brunovieira.comunica@gmail.com 


\begin{tabular}{|c|c|}
\hline Histórico & $\begin{array}{l}\text { Submissão: 06/07/2020 } \\
\text { Revisão: 30/07/2020 } \\
\text { Aceite: 31/07/2020 }\end{array}$ \\
\hline $\begin{array}{l}\text { Contribuição } \\
\text { dos autores }\end{array}$ & $\begin{array}{l}\text { Concepção: J.A.M. } \\
\text { Coleta de dados: R.A.S., S.B.S., A.C.H.S. } \\
\text { Análise de dados: R.A.S., S.B.S., A.C.H.S. } \\
\text { Elaboração do manuscrito: J.A.M., D.S.S.L., I.N.F.S., V.F.C. } \\
\text { Revisões críticas de conteúdo intelectual importante: } \\
\text { B.V.S., H.L.S., J.A.M. } \\
\text { Aprovação final do manuscrito: J.A.M. }\end{array}$ \\
\hline $\begin{array}{l}\text { Consentimento } \\
\text { de uso de imagem }\end{array}$ & Não se aplica. \\
\hline $\begin{array}{l}\text { Aprovação, ética } \\
\text { e consentimento }\end{array}$ & $\begin{array}{l}\text { Projeto aprovado pelo comitê de ética da UFPE, inscrição no CAAE } \\
35080620.3 .0000 .5208\end{array}$ \\
\hline Financiamento & Não houve financiamento. \\
\hline
\end{tabular}

